
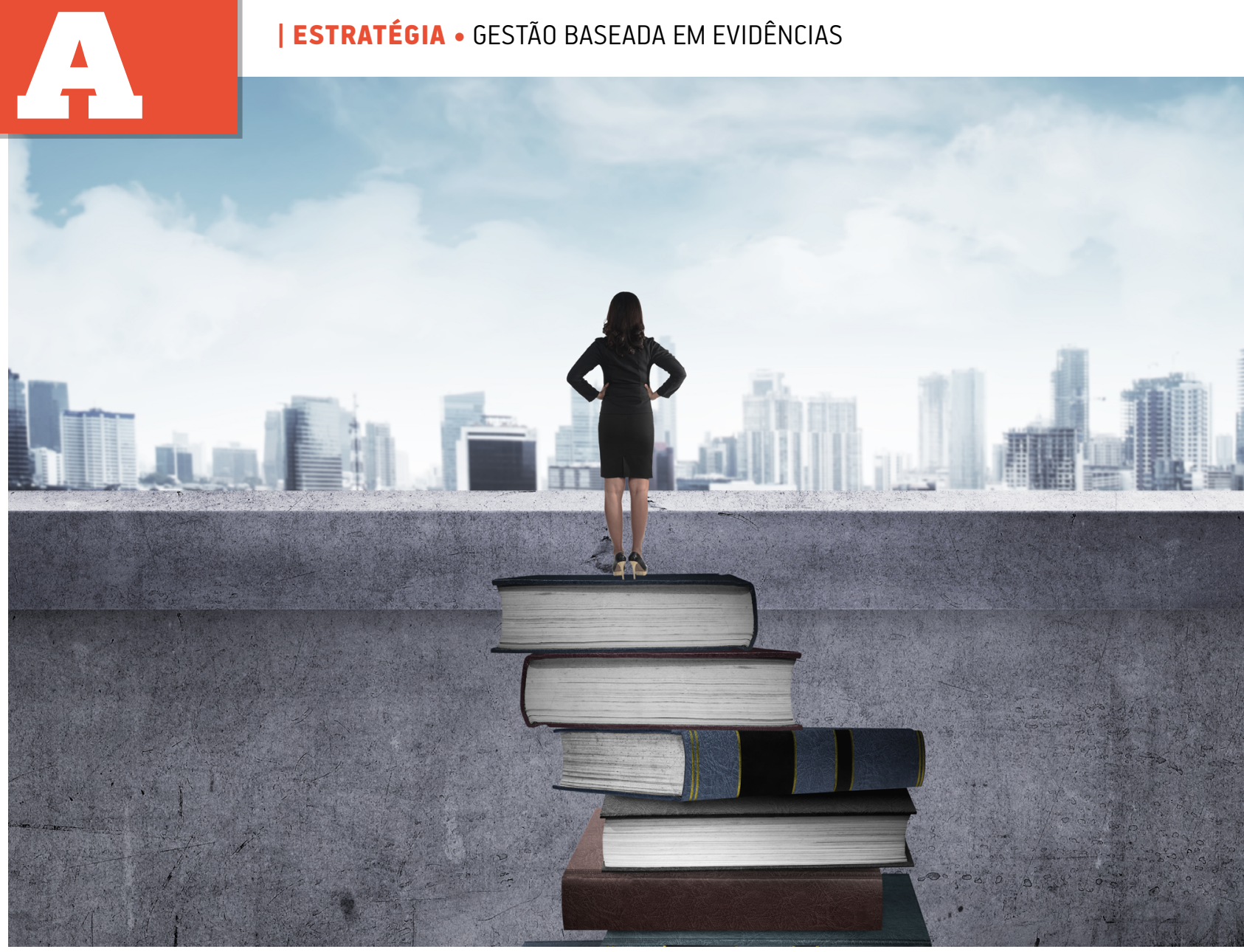

\title{
GESTÃO BASEADA EM EVIDÊNCIAS
}

\begin{abstract}
PARA EVITAR INVESTIR EM PRÁTICAS INEFICAZES, SÓ HÁ UMA SAÍDA: MERGULHAR NOS FUNDAMENTOS DA BOA ADMINISTRAÇÃO E IR EM BUSCA DE FONTES CONFIÁVEIS DE INFORMAÇÃO PARA AS TOMADAS DE DECISÕES.
\end{abstract}

\section{| POR AMÉRICO RODRIGUES DE FIGUEIREDO}

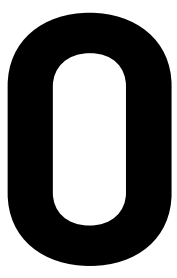

universo executivo costuma enaltecer a vaidade dos seus protagonistas. Chief executive officers (CEOs) atuam como celebridades, excessivamente preocupados com sua imagem pessoal, às vezes mais do que com os resultados das empresas que dirigem. Esse comportamento estende-se a todos os níveis da cadeia de gestores organizacionais. Basta ver o que se publica diariamente no LinkedIn. É uma profusão de mensagens superficiais, caracterizadas por modismos, clichês, estrangeirismos, frases de efeito. Uma verdadeira pirotecnia, a criar a ilusão sobre novas tecnologias gerenciais, vendidas pelos 
seus disseminadores como a panaceia para os desafios empresariais contemporâneos.

Há uma visível superficialidade nas práticas gerenciais, inspiradas por gurus que são hábeis em transformar conceitos consagrados da moderna administração em novas roupagens e neologismos. Gestão de pessoal transformou-se em gestão estratégica de pessoas, depois em gestão de talentos, até que evoluiu para People Analytics e RH 4.0. Gestão de equipes agora denomina-se de squads ou agile teams; cuidar dos clientes virou customer experience, jornada do cliente e experiência do cliente; mudança empresarial apresenta-se como change management ou transformação digital, esta a bola da vez; novos negócios soam melhor como startups; e por aí vai.

São sinais da preferência dos gestores ao pop management, o qual, via de regra, está associado ao imediatismo, à superficialidade das análises e ao que caracterizo como certa ingenuidade executiva. Acredita-se que resultados são produzidos mediante alguma ação performática, fragmentada e isolacionista, sem conexão com os fundamentos da boa administração, ensinada no Brasil há mais de 60 anos.

\section{SEGREGAÇÃO ENTRE TEORIA E PRÁTICA}

Há um desafio de conciliação entre os acadêmicos e os gestores empresariais, ainda habitando mundos à parte. Se de um lado executivos se afastaram dos fundamentos da boa administração, do outro a academia produziu uma fragmentação teórica no campo da ciência da administração, dificultando a visão de conjunto sobre o que advogam as várias escolas de pensamento, sobretudo de como se relacionam.

É preciso destacar que a segregação entre a academia e os gestores reforça o distanciamento entre a teoria e a prática, induzindo ao isolacionismo de ambas as partes, em detrimento dos resultados das organizações e, por que não dizer, da competitividade e relevância delas no mercado. Essa segregação contribui para a profusão do pop management, da gestão mais superficial e imediatista.

A intersecção entre os mundos da academia e das empresas está em uma gestão baseada em evidências. O pressuposto básico dessa prática é a combinação de pensamento crítico e analítico com a tomada de decisões por meio do uso consciente, explícito e criterioso das melhores evidências possíveis capturadas do contexto organizacional e mercadológico.

A maioria das decisões de gestão não é baseada nas melhores evidências disponíveis. Em vez disso, os executivos costumam agir assentados unicamente em sua experiência pessoal. No entanto, o julgamento pessoal, por si só, não é fonte de evidência muito confiável, porque é altamente suscetível a erros sistemáticos - os limites cognitivos e de processamento de informações tornam-nos propensos a preconceitos e a vieses inconscientes, que têm efeitos negativos sobre a qualidade das decisões que tomamos, em prejuízo das organizações para as quais trabalhamos. Mesmo executivos experientes, com muitos anos de atividade, costumam ser ineficazes na tomada de decisão.

Como exemplo, vale destacar uma pesquisa com 950 executivos de recursos humanos (RH) americanos publicada na Human Resource Management, a qual apontou severas discrepâncias entre o que os executivos pensam que seja eficaz e o que os resultados das pesquisas científicas revelam. Os maiores gaps não foram encontrados em questões marginais da área de RH, mas em duas temáticas centrais: como selecionar as melhores pessoas e como motivá-las efetivamente. Os resultados sugerem que a maioria dos executivos de RH atribui pouca ou nenhuma atenção à evidência científica ou organizacional, colocando, em vez disso, muita confiança em evidências de baixa qualidade, como julgamento pessoal, experiência e melhores práticas.

Pesquisas em RH vêm mostrando que gestores que leem a literatura acadêmica e seguem práticas da área comprovadas cientificamente contribuem com resultados financeiros superiores para o negócio. Portanto, ao se distanciarem do estado da arte da pesquisa, ou seja, do mais alto nível de desenvolvimento acadêmico alcançado até o momento, os executivos estão, no mínimo, deixando de dar o retorno que poderiam às empresas em que trabalham. Bilhões de dólares acabam sendo gastos em práticas de gestão ineficazes ou mesmo prejudiciais para as organizações, seus membros e seus clientes.

\section{QUATRO FONTES DE EVIDÊNCIAS}

As evidências para as tomadas de decisões podem vir de pelo menos quatro fontes. A primeira são os resultados de pesquisas científicas, o que exige saber navegar nas bases de dados acadêmicas para encontrar estudos confiáveis a respeito do dilema que precisa ser resolvido.

A segunda fonte é formada por informações levantadas dentro da própria organização, como dados financeiros e estatísticas que medem da satisfação de clientes ou empregados à devolução de produtos, além de pesquisas que avaliam diferentes percepções sobre determinado tema, como a cultura organizacional. Eric Barends, Denise Rousseau e Rob Briner, em publicação do Center for Evidence-Based Management, citam o exemplo de uma empresa que planejava mudar sua estrutura de divisões regionais para por produtos. No entanto, após pesquisa com dados internos, 


\section{MITOS X REALIDADES SOBRE PRÁTICAS BASEADAS EM EVIDÊNCIAS}

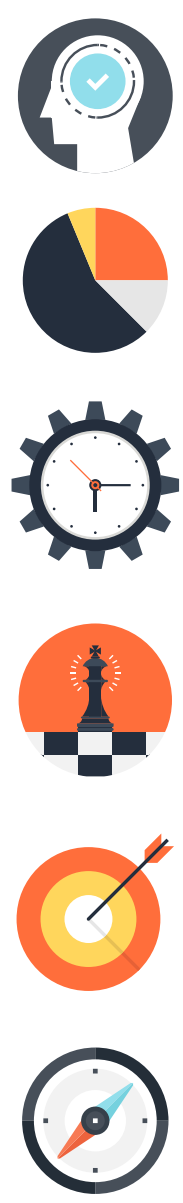

Mito: Ignora a experiência profissional do executivo.

Realidade: Usa várias fontes, inclusive a experiência profissional.

Mito: É só sobre números e estatísticas.

Realidade: A análise quantitativa não é a única fonte usada para a prática baseada em evidências, mas o pensamento estatístico é um elemento importante no processo de tomada de decisão.

Mito: Os executivos precisam tomar decisões rapidamente e não têm tempo para a prática baseada em evidências.

Realidade: A maior parte das decisões leva tempo para ser tomada, mas, quando é o caso de uma resposta rápida, um executivo acostumado com evidências antecipa quais serão exigidas para levantar o que está disponível e lidar com suas limitações.

Mito: Cada organização é única. Assim, a utilidade da evidência científica é limitada.

Realidade: Embora seja verdade que as organizações diferem, elas tendem a enfrentar problemas semelhantes, e muitas vezes, respondem a eles de maneiras similares. As decisões têm de ser tomadas considerando semelhanças e particularidades.

Mito: Se não há evidências de alta qualidade, você não pode fazer nada.

Realidade: Às vezes há pouca ou nenhuma evidência de qualidade disponível. Nesses casos, o executivo não tem outra opção a não ser trabalhar com a evidência limitada disponível e complementá-la por meio do processo de aprender fazendo e de testes piloto para analisar os resultados.

Mito: Evidências de boa qualidade indicam a resposta para o problema.

Realidade: Os executivos que estão acostumados com evidências costumam tomar decisões não baseadas em informações conclusivas, sólidas, atualizadas, mas em probabilidades, indicações e conclusões tendo em vista cenários. A evidência não thes diz o que decidir, mas ajuda-os a tomarem decisões mais bem fundamentadas.

\section{FONTE: EVIDENCE-BASED MANAGEMENT: THE BASIC PRINCIPLES, 2014}

descobriu-se que os representantes de vendas que conseguiam melhores resultados eram aqueles que viviam próximos aos consumidores que atendiam, evidência que demoveu o Conselho de Administração de fazer a mudança.

A terceira fonte está na experiência profissional. Conhecimento específico é acumulado com o tempo para saber como lidar com diferentes situações. Então, diante de uma decisão, é possível fazer um levantamento para acessar esse conhecimento.

A quarta fonte são os valores e as preocupações das partes interessadas. A organização pode utilizar diferentes técnicas de pesquisa para entender o que pensam aqueles que serão afetados pelas decisões, o que ajudará a compreender quais serão suas reações e até a projetar o resultado das medidas.

Essas fontes não são excludentes. Cruzar percepções das partes interessadas com a experiência de profissionais, os dados das organizações e as pesquisas científicas é uma forma de fazer uma sintonia fina, eliminar ruídos e ter melhor embasamento para as decisões. Mas nem sempre todas as fontes de evidência estão disponíveis ou compensam financeiramente o esforço. Nesse caso, vale sempre questionar a melhor evidência disponível para tomar determinada decisão. Uma visão crítica e baseada no princípio da práxis, que se nutre pela análise racional de qualidade, alicerça uma gestão baseada em evidências.

\footnotetext{
PARA SABER MAIS

- Eric Barends, Denise M. Rousseau e Rob B. Briner. Evidence-Based Management: The Basic Principles, 2014.

- Gibson Burrell e Gareth Morgan. Sociological Paradigms and Organisational Analysis: Elements of the Sociology of Corporate Life, 2005

- Sara L. Rynes, Amy E. Colbert, Kenneth G. Brown. HR Professionals' beliefs about effective human resource practices: correspondence between research and practice. Human Resource Management, v.41, n.2, 2002. doi.org/10.1002/hrm.10029

- Thomaz Wood Jr., Miguel Caldas e Renato Souza. Aproximando Gregos e Troianos. GV-executivo, v.17, n.2, 2018. Disponivel em: rae.fgv.br/gv-executivo/vol17-num2-2018 aproximando-gregos-troianos

AMÉRICO RODRIGUES DE FIGUEIREDO > Doutorando in Business Administration (DBA) da FGV EAESP, conselheiro consultivo e professor de gestão de pessoas, Governança e Organizações > figueiredo.americo60@gmail.com
} 